\title{
Arsenic toxicity, health hazards and removal techniques from water: an overview
}

\begin{abstract}
Arsenic contamination in water, especially groundwater, has been recognized as a major problem of catastrophic proportions. The toxicology and health hazard also has been reported for many years. Because of the recognition that arsenic at low concentrations in drinking water causes severe health effects, the technologies of arsenic removal that have become increasing important. The current regulation of drinking water standard is become more stringent and requires arsenic content to be reduced to a few parts per billion. There are several treatment methods capable of this level of performance ' membranes, coagulation, anion exchange, disposable iron media, softening etc. Treatment cost, operational complexity of the technology, skill required to operate the technology and disposal of arsenic bearing treatment residual are factors should be considered before treatment method selection. This paper aims to review briefly arsenic toxicology and hazards and also the previous and current available technologies that have been reported in arsenic removal. Residual generation and disposal after treatment will also be discussed.
\end{abstract}

Keyword: Arsenic; Toxicology; Membrane; Adsorption; Precipitation; GFH; Residual disposal 